\title{
O sofrimento e seus destinos na gestão do trabalho
}

\author{
Suffering and its destines in working management
}

Luiz Carlos Brant 1

Carlos Min ayo Gomez 1

\begin{abstract}
This study tries to define suffering, drawing on Freud's perspectives, and to circumscribe its destines after its manifestation in work. Open interviews were made with workers, managers, health professionals, and also with their families, all of them from a big public company in the services sector, which is in restructuration process, in the metropolitan area of Belo Horizonte. To underpin the data analysis the Hermeneutic-Dialectical Method were used. As a result this study shows the existence of a tran sformation pro cess of suffering into illness in working management. The somatization, psychiatrization, medicalization, medical licen se, hospital internment, and the invalidity retirement constitute some of the suffering destines. Considering that suffering involves an interlocution with the other, we conclude that this transformation is a political process of braking resistance.
\end{abstract}

Key words Psychic suffering, Worker's health, Work management, Organizational psychology
Resumo No presente estudo, buscamos definir o sofrimento a partir da perspectiva freudiana $e$ circun screver os seus destinos, quando manife stado no trabalho. Foram realizadas entrevistas abertas com trabalhadores, gestores e profissionais da saúde de uma em presa pública de grande porte, do setor de serviços, em processo de reestru turação, na Região Metropolitana de Belo Horizonte, bem como com familiares dos trabalhadores. Para a análise dos relatos, recorremos ao método hermenêutico-dialético. Constatamos a existência, na gestão do trabalho, de um processo de tran sformação do sofrimen to em adoe cimen to. A somatização, psiquiatrização, medicalização, licença médica, in ternação hospitalar e a aposentadoria por invalidez figura ram como alguns dos destinos do sofrimento nesse processo. Partindo do pressuposto de que o sofrimento é uma reação do sujei to diante da diversidade da vida, transformá-lo em adoecimen to pa rece constituir, portanto, uma estratégia de queb ra da resistência na gestão do trabalho.

Palavras-ch ave Sofrimen to psíquico, Saúde do trabalhador, Psicologia organizacional, Gestão do trabalho

1 Escola Nacional de Saúde Pública, Fiocruz.

Rua Leopol do Bulhões 1480, Manguinhos, 21041-210,

Rio de Jan eiro RJ.

interfaz@interfaz.com.br. 


\section{Introdução}

Com o avanço da técnica, cuja função é proporcionar maior con forto ao homem, o trabalho, na con temporaneidade, do pon to de vista físico, tornou-se mais leve, mas, em termos psicológicos, vem se configurando como algo árduo, pesado e, ainda, como fon te de com petição. A busca pela sobrevivência vem fazen do de algumas empresas palco de disputas, on de o tamanho já não oferece garantia de permanência num merc ado de trabalho fortem en te com petitivo. Logo, a reestruturação tecnológica e gerencial vem se apresentan do como uma estratégia vital para várias em presas, na era pós-industrial. Grandes transformações organizacionais são vivenciadas como peri go para o conjunto dos trabalhadores, rem eten do-os a freqüentes, múltiplos e inevitáveis sofrimentos, podendo levá-los ao en frentamen to ou à fuga. Para o indivíduo cujo tra balho é subitamen te modificado, a revolução técnica manifesta-se como um outro ameaçador (Levy, 1997). Mas, como fugir quando a em presa é, simultaneamente, fon te de perigo e de sobrevivência? A ansiedade, tão comum diante das elevadas exigências por produtividade e qualidade, a ponta para a possibilidade de uma de s or ganização que envolve tem po e espaço. Ameaçado em sua integridade, o sujeito pode ex peri m entar de s de um simples mal-estar até o pânico. Pa ra muitos, trabalhar e viver tornou-se um perigo, o que vem fazendo dos locais de trabalho uma rede de intri gas particulares e coletivas. No en ta n to, para o sujei to con tem porâneo, esses locais constituem, também, pon tos de en contro consigo e com o outro, onde permanecerão indícios, rastros, recordações, marcas de uma falta, sentimen to de nostalgia, de um passado, no passado (Valadares, 2000).

Pensar o sofrimento e suas vicissitudes como tema de investigação pareceu-nos, inicialmente, algo fora de moda, nesses tempos em que a tônica nas empresas gira em torno "da qualidade de vida”. Ocorreu-nos substituir o termo sofrimento por mal-estar, mas isso remeteria à conotação de uma leve indisposição, o que difere do sen ti do que estamos atribuindo ao termo. Também seria inadequado falar em sofrimento psíquico, como tem sido feito em alguns estudos. Consideramos que o adjetivo "psíquico" permitiria su por a existência de outros tipos de sofrimento. Qualificar o sofrimen to abriria possibilidades de fragmentá-lo em físico, moral, espiritual, entre outros, de acordo com a ideo logia e com o limite do olhar de cada um. Psíquico, assim como mente, é algo misterioso, incapaz de ser descri to nos mesmos termos que nós descrevemos mesas, árvo rese átomos (Rorty, 1999).

No estágio atual do trabalho, o rápido come o pequeno. Não é o grande que come o pequeno. $\mathrm{O}$ depoimento desse gestor de uma empresa pública do setor de serviços, em processo de reestrutu ração - que implicava a passagem da condição de pública para a de economia mista -, situada na Região Metropolitana de Belo Horizon te, a juda a ilustrar as condições dos trabalhadores nesse processo. Os imperativos de mudança organizacional dessa em presa exigiam constantes e abru ptas substi tuições nos cargos de comando, provocando: estranhamento e falta de ação gerencial nos recém-empossados; perplexidade e sentimen to de abandono nos substituídos; e desori entação nos trabalhadores quan to ao exercício de suas funções. Sem autoridade, mas com poderes de chefia, alguns de sses gestores, diante da falta de experiência no manejo dos conflitos e das novas tecnologias, tinham dificuldades em tomar decisões adminis trativas e de oferecer ori entação operacional a seus subordinados. Nesse cenário de grandes mudanças, muitos trabalhadores estavam submetidos a um ritmo de trabalho contínuo sem pausas ou com pausas inadequadas - e viam-se expostos às más condições ergonômicas e ambientais. Os profissionais das unidades a utomatizadas foram avaliados de acordo com o perfil exigido para as novas funções e receberam treinamen to adequado. Mas, para que se possa ter uma idéia da dimensão das mudanças implementadas na empresa, em março de 1999, quando teve início o processo de reestruturação operacional, em uma "filial", no Nordes te do país, o sistema autom a ti z ado processava 10.201 serviços. Em julho, já atingia a marca de 141.744. Muitos trabalhadores estavam sujeitos a uma sobrecarga de trabalho advinda da escalação para fazer horas extras ou mesmo para adiar suas férias como forma de cobrir as ausências de um col ega, licenças médicas, a posent adorias e demissões. O encaminhamento dos não adaptados às mudanças para o setor de saúde era uma das estratégias en contradas para o enfrentamento das dificuldades (Brant, 2001).

Articulandodados de question á rios socioeconômi cos e do Self-Report Questionnaire-20 (SRQ-20), aplicados em 72 ge s tores dessa empresa, Brant e Dias (2004) con stataram que ansiedade, tensão e preocupação constituíram as manifestações mais freqüen tes do sofrimen to 
$(73,2 \%)$. Tri s teza foi a segunda maior manife stação do sof rimen to en tre os gestores $(43,7 \%)$. De forma semelhante, o "cansar-se com facilidade" $(35,2 \%)$ e o "sentir-se cansado o tempo todo" $(23,9 \%)$ foram associados à fadiga. A dificuld ade de realizar, com satisfação, as atividades da vida diária $(39,0 \%)$ e a perda de intere sse pelas coisas $(19,8 \%)$ expre s s a ram uma situ ação de de s pra zer e mostraram o sof rim en toante o co tidiano marcado por atividades sem significação. O sofrimento, que aparece na forma de dores de cabeça $(26,8 \%)$, do dormir mal $(26,8 \%)$, de sensações desagradá veis no estôma go $(25,4 \%)$, má-digestão $(19,8 \%)$, trem ore s nas mãos $(9,9 \%)$ e falta de apetite $(5,7 \%)$, foi identificado como somatização. Esses autores observaram, ainda, a existência de uma associação significativa $(\mathrm{p}<0,05)$ entre gênero e sofrimento; e que a presença de trabalhadores do sexo feminino com sofrimento $(53,3 \%)$ foi significativamente superior a dos trabalhadores do sexo masculino $(16,1 \%)$, o que sugere que os trabalhadores do sexo feminino têm 6 vezes mais chance de apresentar sofrimento que os do sexo masculino.

Para este estu do, buscamos definir o sofrimen to a partir da pers pectiva freudiana e circunscrever os seus destinos, quando manifestado no âmbito da gestão do trabalho, numa organização em processo de reestruturação. Sob essa pers pectiva, realizamos uma investigação na empresa, anteriormente citada, limitandonos à regi onal de Belo Horizon te. Tran sformada em empresa pública em 1969, ela conta, na atualidade, com 81.995 trabalhadores diretos e o utros 20 mil indiretos, no país. Em Minas Gerais, são 7.622 efetivos e, na Gran de Belo Horizonte, 3.326. Seus trabalh adores são admitidos por meio de concurso públ i co para cargos prédeterminados, no regime da Consolidação das Leis Trabalhistas (CLT). Pa ra a pesquisa, recorremos a en trevistas abertas com 13 trabalhadores; 8 familiares de trabalhadores; 13 ge s tores e 8 profissionais da saúde, de ambos os sexos. $\mathrm{Pa}$ ra a análise dos relatos obtidos, empregamos a metodologia hermenêutica-dialética (Minayo, 1996; Minayo e Deslandes, 2002).

\section{Medo, ansieda de e angústia: definindoo sofrimen to}

Iden tificar as vicissitudes do sofrim en to manifestado exigiu uma clara compreensão do que está vamos den ominando como sofrimen to pa- ra, em seguida, verificar seus destinos. Para Freud (1920), o sofrimento estava relacionado com o peri go. Assim, a ansiedade (angst) descreve um estado particular de espera ou prep aração para o perigo, ainda que desconhecido. O temor (furcht) exige um objeto definido do qual se tenha receio (fürchtet). O susto ocorre quando o sujeito se dep a ra com um peri go sem estar preparado para enfrentá-lo. Portanto, o sofrimen to se configura como uma reação, uma manifestação da insistência em viver sob circunstâncias que, na maioria das vezes, não são favorá veis. A vida, nesse sentido, é árdua e proporciona sofrim en tos diversos, decepções e ta refas impossíveis.

As palavras alemãs angst, furcht e lust, comuns na obra de Freud, figuram em algumas traduções para o português como ansiedade, medo e disposição, em geral, de forma imprecisa e indevida. Em alemão, o termo angst signif ica "m edo" e liga-se a uma pron tidão reativa ante o perigo. Em português, essa palavra foi traduzida como "ansiedade", seguindo a verten te da tradução inglesa, ou como "angústia", con forme a tendência francesa. Já o vocábulo furcht (recei o, temor) não abarca o pânico ou $\mathrm{p}$ avor imedia to, estando mais assoc $\mathrm{i}$ ado à preocupação. A angst é mais vis ceral, imediata, e indica uma reação intensa perante a ameaça de aniquilamento ou dano (seja ela real ou imaginária, es pecífica ou gen érica).

Quanto ao termo lust, ele nos ajudou a pensar as relações entre sofrimento e prazer. Para Hanns (1996), não há, nessa palavra, do pon to de vista lingüístico, nada que se relacione com a sensação de alívio pela cessação do desprazer ou devi do à descarga de pressão. Pelo con trário, lust e stá relacionado, irredutivelmente, com sensações pra zerosas e a uma animada disposição para certas ações. O autor con clui afirm a n do a existência de um hiato entre aquilo que o termo de signa como prazeroso e a concepção de lust como "descarga" que traz alívio para um desconforto (unlust, desprazer). Estabelecendo uma relação essencialmente quantitativa e de caráter fisiológico, Freud partia do princípio de que o prazer/disposição (lust) se caracteriza por ser uma sensação de alívio pela descarga da tensão, e o desprazer (unlust) por ser um acúmulo de tensão devi do a um excesso de estimulação. É a partir da el aboração da pulsão de morte, da questão do masoquismo e da compulsão à repetição que Freud começa a relativizar a sua concepção mais estritamente quantitativa de lust, passan- 
do a abordar os aspectos qualitativos, recon ciliando, assim, o seu signific adolingüístico: Não se pode duvidar que há tensões pra zerosas e relaxamentos desprazerosos. Prazer (lust) e desprazer (u nlust), portanto, não pod em ser referidos a um aumen to ou diminuição de uma quantidade de tensão, em bora mu i to tenham a ver com esse fator (Freud, 1924).

Se exis te tensão prazerosa e pra zer no sof rim en to, qual a razão de se repre s entar determ in ada ex periência como sofrimen to e não como pra zer? Em Freud, temos duas possíveis respostas. Primeiro, haveria uma disposição do sujeito produzindo, simultaneamente, satisfação (befriedigung) e vontade/necessidade (drang). Lust produziria sensações ren tes ao corpo, mesdando-se com vontade e disposição; ou seja, aquilo que, na língua portuguesa vulgar, ficou denomin ado como "tesão" (Hanns, 1996). Segun do, lust estaria relacion ado com a alternância en tre tensão e prazer, em que o suj ei to bu sca ria sati sfação nas situações de contraste e não em um determinado estado de coisas: Quando qualquer s i tuação desejada pelo princípio do pra zer se prolonga, ela produz tão-somen te um sentimen to de contentamento muito tênue (Freud, 1930), ou s eja, inicia-se, nessas circunstâncias, o percurso do sofrimento.

No que diz respei to às fontes do sofrimento, temos: o próprio corpo - con denado à decadência e à dissolução; o mundo externo que pode voltar-se contra comunidades inteiras, com forças de destruição esmagadoras e impiedosas; e, por fim, os relacionamentos com os outros hom en s. O sofrimen to originário do conjun to das relações entre os sujeitos "talvez nos seja mais penoso do que qualquer outro" (Freud, 1930). No entanto, a partir da psicanálise, o peri go não pode ser con si derado apenas algo ex terno. Com a des coberta do inconsciente, de s fez-se a fron tei ra en tre interi or e exteri or, abrin do caminho para situações que ameaçam o ser humano a partir de sua própria in terioridade, fa to que instaura novas dimensões do sofrimen to, onde o homem constata que não é, inteiramente, senhor de seus atos, e que a consciência não abarca a totalidade da sua existência. Logo, o destino dado às manifestações do sofrimen to pode levar a uma intensificação ou conservação, ao aumento ou diminuição da vontade de viver, mas sempre portan do as marcas tanto do próprio inconsciente quanto dos dispo s i tivos do mu $\mathrm{n}$ do institucional ao qual se está ligado - en tendendo-se por dispositivos o conjunto de mecanismos institucionais para alcançar uma nova ordem, aliados à disposição do sujeito para atingir um fim (Brant, 2004).

Para Freud, a civilização se constrói sob a é gi de do sacrifício. Os pra zeres da vida civilizada são acompanhados de sofrimento e a satisfação su r ge con comitan te ao mal-estar. Compulsão, regulação, recalcamento ou renúncia forçada são mal-estares da modernidade, resultantes do "excesso de ordem" e de sua inseparável companheira, a "escassez de liberd ade". Em sua leitura de $O$ mal-estar na civilização, de Freud, Bauman (1998) con clui que os sof rim en tos advin dos do frágil e sem pre decaden te corpo, do cruel e impiedoso mundo, e dos agressivos seres humanos têm sua ori gem no cercea men to à liberd ade em busca do prazer. No entanto, nossas obs ervações empíricas indicaram a existência não apenas de um movimento dos trabalhadores pela liberdade, mas, também, de uma busca por proteção contra as ameaças que colocam a vida em risco. Algumas vezes, a árdua tarefa de sustentar-se colocava a luta pela liberdade em segundo plano, principalmente, entre aqueles que viviam do trabalho. No caso dos assalariados, o sofrim en to surgia como el em en to cen tral de uma relação marcada pelo conflito entre submissão e resistência. No entanto, parecia não haver espaço, nas empresas, para a mani festação desse sofrim en to, geralmente representado como fraqueza. Trabalhadores e ges tores eram capazes de admitir uma doença, mas não o sofrimento (Brant, 2001). Constatações como essas leva ram-nos a postular a existência de um processo de tran sformação de sof rim ento em adoecim en to, na gestão do trabalho. Partin do do princípio de que o sof rim en to constitui-se como uma dimensão alteritária, en dereç ada a um interloc utor, levantamos a hipótese de que essa transformação constituiria um processo político de quebra da resistência dos trabalhadores, pois "é no interi or do espaço da fábrica pós-classe que uma nova figura do trabalhador en con tra seus limites, suas marcas e o s eu modo prático de expressão e de ação" (Lazarus, 2001).

A definição de Freud para sofrimento e a sua noção de inconscien te - um verdadei ro bastidor onde ocorre invenção de metáforas, deslizes e cen sura da memória, delineamen to de sonhos e de desejos - pareceram-nos adequadas, mas insuficientes para os nossos objetivos. Caso nos restringíssemos à perspectiva freudiana para com preender e circunscrever o sofrimen to e seus destinos, na gestão do traba- 
lho, correríamos o ris co de ficar limitados aos mediadores lingüísticos, pois Freud cons erva ainda uma tradição platônica, em que a linguagem é tratada de forma abstrata, transcendental e interna à própria linguagem, não con templando, devidamente, os mediadores sociofuncionais que ocorrem no interior das instituições. Con si deramos a linguagem dos trabalhadores também instrumen to, e não, unicamente, um conjunto de repres entações - mecanismo que modifica os seus usuários e os produtos de seus usos. Portanto, a trama de crenças dos en trevistados, ex pressa em seus depoimentos, é abordada não apenas como lugar de elemen tos lingüísti cos auto - reformuladores, mas também de el emen tos de recon tex tualização do sofrimen to, implicando o sujei to no seu destino (Rorty, 1999; 2002). Buscamos estabelecer uma articulação entre os dispositivos de gestão e a linguagem, ou seja, identificar os destinos do sof rim en tomanife st ado também a partir da dimensão ético-política. Seguindo a orientação foucaultiana, conduzimos uma investigação dos modos con c retos com que o poder pen etra no corpo, no comportamento e nas formas de vida dos trabalhadores. Tratamos, a seguir, de alguns dos de stinos do sof rim en to constatados em nosso estu do, eviden cian do como a em presa assume e integra em sua esfera a "atenção à saúde do trabalhador".

\section{Somatização: uma tentativa de localização do sofrimen to no corpo}

Para alguns médicos entrevistados, os primeiros "surtos de dor", entre os trabalhadores, reconhecidos por eles como reais, coincidiram com o início do processo de reestruturação da empresa e estavam con centrados na área operacional. O ambi en te on de exerciam suas repetitivas atividades raramen te era mencionado. Cumpre obs ervar, no entanto, que havia situações em que o trabalhador realizava, com o braço, dois mil movimentos por hora, cumprindo a meta estabelecida para uma determinada tarefa. Os imensos galpões permitiam ampla visibilidade. Havia de zenas de homens trabalhandoem pé, diantede gran des armários de madeira. A maioria, em silêncio, olhava fixamente vários objetos contidos em uma das mãos, enquan to o braço levantava e abaixava, sincronizadamente, colocando-os em 40 pequ enos escaninhos. Enquan to isso, um supervisor, com relógio em punho, prancheta nas mãos, e o olhar concentrado no trabalhador, c ronometrava. Para efeito de avaliação de desempenho, a margem de erro tolerada era de $3 \%$. Rapidez e agilidade eram os quesitos mais valorizados, pois todas as en comendas recebidas deveriam ser envi adas aos seus de stinos no mesmo dia, in depen den temen te do número de hom ens e de obj etos.

Em 95, quando iniciou a reestruturação, as do res su rgiram, realmente. Elas não existiam antes, en tendeu? A maior queixa era ortopédica, lá do cen tro opera cional, onde a pessoa triava mu ito (C. O., profis sional da saúde, 32 anos). Esses profissionais da saúde recon h eciam que as mudanças nos processos de trabalho, juntamente com a introdução de novas tecnologias, impunham profundas alterações na forma de trabalhar. Sa biam que a acel eração do ritmo de trabalho e a imposição de maior responsabilidade sobre o produto final constituíam as maiores pressões e con sideravam que as transformações - verd adei ras con quistas administra tivas - não eram acompanhadas de melhorias nas condições de trabalho, pelo menos numa proporção equ ivalente. Para Coelho e Reis (1998), prof undas mudanças organizacionais na área operacional, que não con templam, da mesma forma, as condições de trabalho, produ zem impactos s obre a saúde, com prom etendo, principalmen te, o sistema músculo-esquelético de um grande número de trabalhadores.

Em alguns setores operaci onais da empresa pesquisada, a estrutu ra real não corre s pondia à planejada, como aquele em que atuava I. E., 47 anos, cujo efetivo era de 36 trabalhadores, tendo sido proj et ado para 60 homens. Esse trabalhador afirm ava: Minha tarefa está muito pesada. Estamos com nosso efetivo reduzido, tenho que desd obrar. Pro cu rofazer o melhor que posso. Minha LER (Lesão por Esforços Repetitivos) está aumentando a cada dia. Marquei um médico para a próxima semana. Queixas como essa eram escutadas com desconfiança, principalmen te quando a palavra LER era mencionada. O depoimento seguinte confirma essa percepção: Dor real é o seguinte: a pessoa ch ega lá e fala, "eu estou com LER". A LER não existe. Você tem que ter a lesão gerada por um trauma no trabalho, ela acomete um seguimento, ela não acomete o corpo inteiro (C. O., profissional da saúde, 32 anos). A partir daí, a atenção médica se fazia por meio de proced im en tos inve stiga tivos, na ten ta tiva de localizar a ori gem dessa dor na disfunção de alguma parte do corpo. Esse era o pressupos to que norte ava os cuidados. 
Além da definição diagnóstica, buscava-se também averiguar a veracidade ou falsidade da queixa. Se as "lesões por esforços repetitivos" constituem ou não um genérico diagnóstico sindrômicoé uma questão polêmica, que não cabe aqui discutir. Segun do essa con cepção, a dor só pode ser fruto de uma lesão. Portanto, a quilo que é chamado de dor, s em comprom etim en to de alguma estrutu ra física, constituiria uma falsa dor. Seguindo essa lógica, não é apenas a "LER" que não é reconhecida, mas a diferença entre dor e essa outra dor, que denominamos sofrimento.

Diferen temen te da dor, o sofrimen to possui uma dimensão política, uma vez que envolve a presença "do outro" (o "tu") no campo da existência do sujeito. Portanto, a redução do sofrim en to apenas à dimensão da dor con stitui um obstáculo ao caminho alteritário. E, assim, pode dificultar a indagação pelas implicações da or ganização do trabalho nas qu eixas de dor. O não reconhecimento do sof rim en to favorece a regressão do alteritário a um certo solipsismo. A queixa, como ato de reclamar a outrem que, supostamente, tem autori d ade para modificar procedimentos indevidos de um terceiro não era levada em con si deração. Auscultavamse os sons do corpo - batimento cardíaco, ritmo respiratório e pulsação -, mas não se escut ava o trabalhador, que, em sua linguagem, se referia ao sof rimento como "LER". Ao ser escutado como algo desabitado da linguagem, a manifestação do sofrimento perdia a sua condição alteritária. Sendo abordado em termos médicos apenas na dimensão da dor, o sofrimen to era vis to, assim, como mais um el em ento que compõe a dimensão somática. Aí fui ao médico, nunca tinha sen tido aquela dor antes de ir pa ra aquele setor, eu queria saber o que era. Mandouti rar a blusa, escutou o co ração, a pertou meu corpo aqui, ali, olhou minha pressão. Disse que, no princípio, todo mundo reclama a mesma coisa. Mas, depois passa (R. M., atenden te comercial, 42 anos).

O desejo dessa trabalhadora de compreender algo a respeito de si mesma, em sua nova função - que poderia estar se manifestando através da dor - não era escutado como parte do sofrimento. Em seu lugar, apenas o corpo era examinado. "Vale dizer, o poder se materi alizariae se exerceria sem pre sobre o corpo, s endo este o lugar, por excelência, pa ra a dominação do poder" (Birman, 2000). Negligenciado em sua dimensão de sujei to, o trabalhador era vis to apenas como paciente; era submeti do ao exame físico e a exames labora toriais. Quando os result adbs eram negativos, portan to in compatíveis com a queixa, procediam-se a novas investigações. Nos casos, que não eram raros, em que nada se detect ava, as qu eixas eram analisadas como fingimen to para se esquivar de um trabalho desagrad á vel, pre servar o emprego ou mudar de cargo. Julgaram que era uma simples coisa, mau jeito. Eu dizia que era como dor de doente. Falaram para fazer Raio X e chapas. Não constatou nada. Pedi afastamen to, não estava agüentando a furadeira. Depois, foi mesmo o chefe que pediu o tratamento. A área da saúde duvidava da minha dor, ach avam que eu queria mudar de setor. Por muito tem po, eu nada podia fazer para provar minha dor; comecei a beber mais, ajuda a aliviar a dor (I. E., 47 anos, trabalhador do setor operacional).

Como uma espécie de jogo, de prova, desafio lançado por um adversário ao outro, o trabalhador não tinha outra escolha senão submeter-se, pois renunciar equ ival eria a decl a rarse farsante. A verdade era a verdade médica. Com esses pressupostos, p a recia não ex is tir lugar para o trabalhador e seu sofrimen to, apenas para o paci en te e sua dor. Isso significa dizer que a qu eixa de um trabalhador não se resume à qu eixa de um paciente, e que sof rimento e dor se diferenciam.

Portanto, designamos por somatização o processo de investigação do sofrimento, a partir de recursos instrumentais, com o objetivo de localizá-lo apenas na dimensão corporal. Constatamos que as abordagens que iam da simples apalpação às mais sofistic adas tecnologias médicas ten tavam detectar estruturas orgânicas danificadas para ju s tificar a dor. Nesses casos, tanto o exame físico quan to os achados de exames labora toriais eram notórios pela ausência de elemen tos capazes de dar sustentação às queixas. $\mathrm{O}$ resultado era sempre a inexistência de um diagnósti co con clu sivo. A lógica subjacen te era que toda dor tinha, obrigatoriamente, uma inscrição no corpo, sen do o bastante mapeá-la, procedimento que remetia o profissioml à inevitávd pergunta, "on de dói?" Nada sen do detectado, o diagnósti co mais comum era o de "probl emas emocionais".

Con cluímos que a queixa de dor, em geral, in terpretada como sinal de doença, des equilíbrio em ocional ou má-fé, dificilmen te era percebida, pelos médicos, como sofrimen to, no sen ti do freudiano do termo; ou seja, a pre sença de um peri go qua n toà permanência na em presa. No entanto, alguns trabalhadores reconhe- 
ciam seu sofrimen to, recusavam o diagnóstico de simples doença e buscavam articulá-lo ao cargo, exercido com temor (furcht). Eu chego chorando, com raiva, isso acontece comigo, mas acontece com o geren te também. Isso passa a ser visto como parte da minha fragilidade e não do processo da organização (F. R., profissional da saúde, 34 anos). Esses trabalhadores tinham dareza do receio e o rel acion avam à ree s truturação do trabalho. Mas sabiam, também, que a sua manifestação era vista como desequilíbrio emocional, tornando-se alvos daquilo que é comumen te chamado de "culpabilização da vítima”. No entanto, esse saber era insuficientepara escaparem ao destino dado ao conjunto dos trabalhadores, nessas circunstâncias. Devi do a uma con junção de interesses, algumas manife stações do sofrimento tinham gran de visibilidade, situação que contribuía para a consolidação da imagem de profissional problemático. Algumas dessas manifestações eram interpret adas como depressão e recebiam encaminhamen to psiquiá tri co.

\section{A psiquiatrização}

As exigências conven ci onais de um processo de reestruturação tecnológica e gerencial, somadas ao aumen to do número de assaltos na empresa, criavam um ambi en te propício ao cansaço, à tristeza e ao medo. A psiquia trização é o processo pelo qual o sof rimen to rel acionado a essas situações era diagnosticado como transtorno mental, receben do indicação para tratamen tos psicoterá picos e/ou psiquiátricos.

Ser uma profissional do campo da saúde possibilitava a F. R. uma leitu ra apurada da psiquiatrização do sof rimento, mas esse conhecimento não era capaz de impedir que ela mesma fosse envolvida nesse proces s o. Em sua entrevista, que ocorreu durante o perí odo em que estava de licença médica, e fazen do uso de antidepressivos, afirmou: As pes soas vão ch egando a um esgotamento. Ai entra a psiquiatrização. É mais fácil admitir que estou deprimida do que ver que minha relação profissional está me esgotando. Ai eu me transformo num paciente psiquiátrico, aí eu vou tomar medicação pa ra eu dar conta de trabalhar (F. R., profissional da saúde, 34 anos).

Durante a reestruturação, a demanda no setor de saúde aumentou, sobrecarregando a en trevistada. Para F. R., o cansaço estava relacionado às transformações da empresa, que, por sua vez, estavam vinculadas a um governo federal em processo de mudança. Você não tem cla reza do processo, tudo pode mudar, de repente, aí dá mu i to med o. A com preensão das qu estões institucionais não impedia o deslocamento das dificuldades relacion adas ao processo de trabalho para si mesma, culpabilizando-se. "Até já disseram que é histeria minha”, afirma a entrevistada. No entan to o sofrim en to mais difícil era admitir que a sua vida profissional estava à mercê de uma transformação sem rumo definido, o que lhe dava medo. Abandon ada às incertezas de um con tex to em que tu do poderia mudar de repente, a iden tidade de deprimida parecia oferecer segurança maior que a de funcionária, pois, como "doente", o emprego lhe era asseg u rado. $\mathrm{O}$ uso de psicotrópicos possibilitava "condições de trabalho", s em dar tanta atenção às questões pessoais e institucionais, mas às custas de afastamentos cada vez mais constantes, ou seja, por meio da tran sformação do sofrim en to em adoecimen to. Esses dispositivos médicos e organizacionais incidiam, particularmente, sobre o corpo feminino, histericizado e patologizado, com o obj etivo de afastá-lo do espaço públ i co, buscando no discurso psiquiátri co do século 19 o delineamen to de duas patologias: a histeria e o masoquismo (Foucault, 1976).

Apaixonado pelo teatro e falando de sua tristeza por ter deixado a carreira artística e o curso de Belas Artes para se casar, J. F., do setor administrativo, 28 anos, afirm ava: A gente va $i$ ficando triste, probl ema com a mulher, a dificuldade do serviço, a falta de dinheiro. Ach ei relaxamen to na bebida. Eu quero crescer na em presa. Mas disseram que tenho depressão por causa de uma substância que está baixa, que é hered $i$ tário, lem b reida minha mãe. A vida dá medo na gente. Com os atrasos, faltas e uso de bebida, esse entrevistado foi encaminhado ao setor de saúde e, em seguida, para tratamento psiqui átrico. Diagnosti c ado como depressivo, passou a fa zer uso de medicação.

A psiquiatrização de situações pró prias da vida humana, como tri s teza e medo, sinalizava o deslocamen to de manifestações típicas da intersu bj etivid ade para o domínio pes soal. Os níveis neu roquímicos e a sua transmissão hered itária costumavam ser as explicações para a disposição ou cansaço, alegria ou tristeza, medo ou altivez. Com essas determinações biológicas, não se perguntava pelas implicações das condições de vida e de trabalho no sofrimento. Assim, a clínica con temporânea, ao esquecer a 
paixão tris te e substituí-la pelas “depressões” e "distúrbios do humor", separava-se de toda uma tradição que, de Aristóteles a Descartes, passando por Tomás de Aquin o, considerava a tristeza não um estado anímico, nem de hum or, mas uma paixão da alma (Andre, 1995).

Afastado da agência devido à síndrome de es tresse pós-traumático e depressão, B. V., gestor, 43 anos, relata: Transportando dinheiro, fui assaltado, com revólver na cabeça. Houve insinuações que eu poderia estar conivente. Eu passava noites sem dormir. Só vendo assaltante na minha cabeça. A assisten te so cial falou: vou te internar num hospital psiquiátrico. Eu vejo vulto, alguém vai me pegar, aí eu aco rdo doido de medo. Olho dentro de casa, no quintal, no armário. Então, são heranças, são coisas que ficaram ali do passado, pre sentes, que eu espero que apague, lo go. Em bora tenha sofri do aci den te de trabalho, esse gestor expressava sua mágoa pela empresa ter duvid ado de sua honestidade, após 23 anos de dedicação. Viu-se violentado; era como se a empresa também o tivesse assaltado. An tes do even to traumático, os assaltantes eram reais e e st avam do lado de fora. "Confiava na empresa como lugar adequado a quem entregava seus di rei tos para guarda" (Bauman, 2001); após o trauma, em seu imaginário, havia lugar para assaltantes que poderiam estar na rua ou nos sonhos. Havia perdido a referência que o trabalho proporcion ava. Heranças de um passado que se presentificaram, também, quando a assistente social o indicou para internação. Pa ra o corpo, ou a sua afecção, a imagem da coisa é a mesma, quer seja de uma coisa passada, futu ra ou presente (Spinoza, 1983). Após se deparar com o peri go, para o qual não estava preparado, quando buscou apoio, esse trabalhador defrontou-se com a angústia e com o desamparo, diante dos quais, a busca desesperada de um o utro a quem oferecer seu corpo e sua alma é uma das saídas possíveis. O indivíduo, ao colar-se no outro, estabel ece uma relação de servidão como forma de tentar evitar a dor do desamparo e afastar-se da angústia (Freud, 1937).

Cansaço, incerteza e decepção, manifestações do sofrimen to, pres en tes nesses três casos, possuíam origens diferentes, mas obtiveram destinos semelhantes. Embora houvesse dúvidas quanto à realização dos proj etos profissionais, duran te a reestruturação, existia também a esperança do su cesso. Entre medos e esperanças, alguns perdiam o limite da dedicação ao cargo, trabalhando obsessivamente ou às custas de medicação. Si tuação usada, muitas vezes, como exemplo pela empresa. Há 7 meses, $B . V$. [gestor, an teriorm en te citado] conseguiu reverter o mau desempenho da agência com boas idéias. Aos sábados e domingos, costuma pegar a máquina auten ticadora e percorrer a área rural e os cinco distri tos re cebendo pagamen to das contas... (boletim interno da empresa). Mas qual é o po n to em que a servidão voluntária dos individuos se co munica com o poder objetivo?, pergunta o filósofo italiano Agamben (2002). A reestruturação organizacional ameaçava a carreira profissional de alguns, suscitando uma divers i$\mathrm{d}$ ade de manifestações de sofrimento que não eram percebidas como reações diante de um peri go iminente, no senti do freudiano do termo. Essas reações eram, então, diagnosticadas como depressão, estresse, fadiga, transtornos obsessivos compulsivos e esgotamento, receben do tratamen to psiquiátrico, produzindo uma interrupção na história de vida e de trabalho. In depen den tem en te da etiologia das qu eixas, os diagnósticos eram desvinculados do processo de trabalho e as prescrições medicamentosas, geralmente, tinham a mesma base farmacológica. Foi possível observar um processo de subjetivação que con duz o sujeito a vincular a identidade e a própria consciência a um poder de controle externo. Portanto, diagn o s ticar algumas das reações dos trabalhadore s como trans tornos psiquiátri cos implicava desconsiderar o momento institucional de reestruturação, o processo de trabalho nesse contex to e existência de um sujeito portador de uma história de vida. Com esses procedimentos, ocultava-se a existência, na gestão do trabalho, de técnicas de indivi dualização subjetivas e procedimentos de totalização objetivos, configurando um verdadei ro "duplo vínculo políti co, constituído pela individuação e pela simultânea totalização das estrutu ras do poder moderno" (Foucault, 1994).

Se, para Freud (1930), a ansiedade, o medo e o su s to rel aci onam-se com o peri go, para Spinoza, no livro III da Ethica, o medo está articu1 ado com o des ejo, a dúvida e a esperança, concluindo que "não há esperança sem medo, n em medo sem esperança” (Spinoza, 1983). O medo con sti tui um bem do sujeito e, portanto, a medicalização do medo é um perigo. Ao proporcionar uma segurança (securitas) ilusória, elimin a ndo-se o medo, suprime-se também a dúvida e, com ela, a esperança. O diagnóstico de fobia para o medo impede a incômoda pergunta: "o que está acon tecen do comigo?" - em seu lugar, fica a explicação médica mais comum, a 
de um tran stomo neu roquímico. Ao anestesiar o medo, apagam-se, também, o desejo e a po ssibilidade de ação transformadora: Quanto maior é a tris teza tanto maior é a capacidade de agir com a qual o homem se esforça pa ra afastar a tristeza (Spinoza, 1983).

\section{Medicalização}

A prescrição medicamentosa não se fazia apenas através dos médicos. Entre os trabalhadores, circulavam diagnósticos e indicações, frutos da experiência empírica: A maioria tem tendinite no ombro. Muita gente fala que tem bico-depapagaio. A gen te vai ao farmacêutico, e o mais comum é comprar Voltaren. Aprendemos isso com os colegas (H. D., trabalhador do setor operacional, 30 anos). O utras vezes, não era necessário ir à farmácia. Cada setor dispunha de uma "pequena farmácia”. A cultura da medicalização parecia estar vinculada às repre sentações essencialmente funcionalistas do corpo, a rticulandose com os destinos da somatização e da psiquiatrização. Como uma espécie de ferramenta, o remédio estava sempre disponível e ajustado para o cumprimento da tarefa, o que o transformava em um verd adei ro elemento "reparador": Tendinite, aí você não funciona direito, trava. Dói como clavícula quebrada. Lá, na seção, temos remédios numa caixa de papelão, tem remédio para dor, mas também tem bicarbonato, água oxigenada, band-aid (G. C., trabalhador do setor operacional, 34 anos). Disponibilizar a medicação no local de trabalho pareceu-nos uma forma de ga ra $\mathrm{n}$ tir aditivos capazes de favorecer o cumprimento de funções, como se o corpo tivesse de ser periodicamente retificado. Algumas vezes, o medicamento no setor não era suficiente, era preciso portá-lo, em caso de situações in esperadas: Trabal ha ndo na rua, desarranjo intestinal é o pior que pode acontecer. Nós usamos mu i to Imosec, quando tamos com piriri, e Buscopan pa ra dor forte. É comum também ter na sacola hidróxido de alumínio para queimação no estômago (L. G., trabalhador do setor operacional, 26 anos). Esses trabalhadores en tendiam que substâncias químicas poderiam "pro teger" o corpo de situações adversas.

Repres en tada como algo mági co, a medicação parecia consti tuir uma ferramenta de trabalho para um bom desempenho, em especial, perante os hiera rquicamen te su periores: Ansiedade não me deixa trabalhar. Tenho ansiolítico na pasta. Só uso no trabalho; é um recurso.
Quando vou apresentar algo ou quando o dima está tenso, eu tomo (S. E., ges tor, 38 anos). Como um instrumen to sem pre disponível, os psicofármacos eram utilizados como se fossem equipamentos de proteção individual. Nesses casos, eles estavam sempre junto do corpo, uma maneira comum, entre os trabalhadores, para lidar com a ansied ade (angst), no senti do freudiano do termo, situação que evi denciava um estado particular de espera ou preparação para o perigo, ainda que desconhecido. Alguns h aviam sido orientados por médicos para usálos quando sentissem tensão, tristeza, apatia e cansaço. Os psicofá rmacos, como estandarte de uma espécie de imperialismo, perm item que todos os médicos - em especial os clínicos gerais abordem da mesma maneira todo tipo de afecções, sem que jamais se saiba de que tratamen to elas dependem... (Roudinesco, 2000). Portanto, os mesmos medicamentos - principalmen te anti depre s s ivos e ansiolíti cos - eram prescritos tanto para trabalhadores que se apresentavam simplesmen te cansados, tris tes e desiludidos, e cuja ansied ade levava a dificuldades para dormir, quanto para aqueles portadores de uma estrutu ra psíquica depressiva ou melancólica.

O mecanismo mais interessante de evitar o sofrimento é aquele que influencia diretamente o organismo, a intoxicação química (Freud, 1930). O uso abu s ivo de substânciasquímicas, tanto as lícitas qua n to as ilícitas, e os períodos de abstinência, enten didos como ex pressões do sof rimento transform ado em ato, frutos da proibição da manifestação pela palavra, na empresa, aliados à subjetividade, com a alternância en tre pra zer (lust) e de s pra zer (unlust), em que o trabalhador buscava satisfação nas situações de con traste, mostraram-se exemplares para esta situação. Os vários casos de medicalização abusiva, entre os en trevistados, demonstra que o sofrimen to é apres en tado como algo vivenciado, solitariamente, no próprio corpo, uma característica de nossa época. Para esses indivíduos, o outro está sempre distante, fa zen do com que a dimensão ética da manifestação do sof rimen to perca o sen ti do sob o aspecto de ped i do de ajuda en dereçado a este outro. Esse "am ortecedor de sofrimen to" proporcionaria não apenas um pra zer imed i a to, mas, também, um grau de s ejado de independência do mu ndo, permitin do ao suj ei to afastar-se da pressão ex terna e refugiarse em si mesmo. Trata-se de uma ten ta tiva del iran te de en contrar uma unidade imaginária que teria por objetivo cimentar uma realidade apreendida como fragmentada. Havia a crença 
de que, uma vez medicados, s eu sof rim en to esta ria dom in ado. Essa busca por alívio dava en sejo ao desespero que, por seu turno, abria as comportas da dependência. A ingestão de pílulas parecia fagocitar, conjuntamente, a angustiante situação de depara r-se consigo mesmo. Fech ada a questão, sepultavam a possibilidade de expressar o sofrimento em palavras e, portanto, a com preensão de sua ori gem.

\section{Licença médica: cuidadoe fon te de sofrimen to}

A licença médica cumpria a função de afastamento temporário da atividade para fins de tratamen to. Termin ado esse período, com a saúde restabelecida, o suj ei to retorn ava. No en tanto, as licenças prolongadas tinham um percurso diferen te, como nos mostra P. K., trabalhador do setor operacional, 41 anos: Eu não sabia o dia da semana, não fazia diferença. Ficava aten to ao oitavo dia útil, para receber, e à data da perícia. Essas datas me ajudavam a saber que dia era. As consultas também ajudavam a marcar o tempo. Em geral, o afastamento tornava-se recorrente e tinha diagnóstico psiquiátrico. Obrigados a perma necerem em casa, $s$ ob a vi gilância da família, perdiam a noção do tem po, que somen te fazia senti do nos mom en tos da medicação. Alguns localizavam o dia da semana através das consultas médicas agendadas; em outros casos, as datas das perícias do INSS aju davam-nos a situarem-se ao longo dos meses.

A esposa de I. E., 47 anos, trabalhadbr do setor operacional, afastado devi do a transtornos osteomusculares, a juda-nos a com preen der um pouco mais o universo doméstico da licença médica: A cada perícia, voltava decepcionado; queria voltar a trabalhar e o médico falava não. Então, co meçouafazer bicos, para ficar fo ra de casa. Tinha vergonha. Toda vez que bebia era a mesma reclamação: não pres to nem pa ra trabalhar, não sirvo pa ra nada. Aí, ele ia pa ra o boteco beber. Acostumado a organizar a vida ocupacional em função do tem po regulado pelo trabalho, I. E. se depa rou com o curto prazo das licenças. A cada três ou quatro meses, não sabia se seria aposentado; não tinha como estabelecer um proj eto de vida. O desejo de retornar à função não era suficiente, uma vez que os exames clínicos e labora toriais não o permitiam. A ordem estabel ecida pela ro tina do serviço tornou-se des ordem. "A ro tina pode degradar, mas também proteger; pode decom por o trabalho, mas tam- bém com por uma vida”, nos diz Sen n ett (2000). Ficar em casa tornara-se, então, sinônimo de inutilidade, e suscitava anti gos conflitos familiares, en cobertos pela permanência co tidiana na em presa, lon ge do ambiente doméstico. Na tent a tiva de en con trar uma rotina, o "fa zer bi cos" também remeteu I. E. à incerteza. Após cada "en comenda", não sabia se haveria uma próxima. A licença médica era também licença da vida. No bar, estabeleceu, gradativamente, uma rotina. Ele ficou, ansioso muitoabalado. No final de cinco anos de afastamen to, já não estava mais agüentando, ele bebeu mais, ficau triste. Aí, já no final, começou a fazer tratamento psiquiátrico, ch egou ao ponto de ser internado. Então, essa licença não foi boa pa ra el e, relata a esposa de I. E., que, como paci en te psiquiátri co, foi aconselhado a retornar ao trabalho, como medida terapêutica. Ainda seg un do sua esposa, voltar foi ótimo, mesmo com dor. Chega, me conta sob re o trabalho. Eu aprendi a me envolver no serviço dele. O que o ch efe imed i a to pode fazer, ele faz. Ele teve apoio do pe s soal da seção.

Se o afastamen to era essencial para o tratamen to, sua prolongação tinha efei tos adversos, principalmente entre os trabalhadores do sexo masculino, lotados no setor operacional. A licença médica implicava não apenas deixar de exercer uma atividade dura e pesada, mas também se distanciar do espaço públ i co como parte de uma cultura essencialmen te masculina (Bourdieu, 1994). Ficar em casa significava fazer parte de um ambien te fech ado, vis to como próprio das mulheres, crianças e doentes, enquanto a rua abria-se como possibilidade de resgate da identidade ameaçada. Diferentemen te da casa, o bar possibilitava instalar-se, novamente, na posição de homem e de trabalhador. Além dos antigos colegas, encon trava também informações sobre a empresa. Entre um trago e outro, era capaz de passar horas a fio falando dos "puxa-sacos", das façanhas sexuais e do futebol. O que con s ti tuía importante estratégia contra o adoecimento era violentamente repudiado pelas esposas. $\mathrm{O}$ bar oferecia satisfação maior que a pró pria casa. A bebida nem sempre era sintoma de dependência etílica, mas desculpa para o en con tro.

\section{A hospitalização}

Algumas vezes, terminada a licença médica, poucos dias após ter retornado ao serviço, ocorria a hospitalização do trabalhador: $E u$ ti- 
nha voltado, estava alegre; mas o supervisor achou que eu estava agitado, que era perigoso continuar. Eu não tinha usado droga. Ele ligou para o setor médico. Acharam que eu não tinha melhorado, aí eles e minha mãe ach a ram melhor me internar. Ele disse que tinha medo de acidente; na verdade, ele não en golia o que eu reclama$v a$ (G. C., trabalhador do setor operacional, 34 anos). A reinserção era sem pre complexa; envolvia o desejo do sujeito, o diagnóstico e o vínculo com o su pervisor. Evidenciava, ainda, a ruptura com os mecanismos defensivos dos trabalhadores (Dejours, 1992). Sob o olhar inquisidor dos colegas e da chefia, qualquer movimento que fugia aos padrões estabelecidos era decodificado como "manifestação da doença" que o afastou. Para a chefia, o tratamento não havia sido completo, o que provava a gravidade do qu ad ro dínico, e uma hospitalização se fazia necessária. Para tanto, o setor médico e a família eram acionados.

A hospitalização como um dos destinos do sofrim en to tinha uma de suas raízes na relação com o ge stor. O pertencimen to ao "nó s" ou ao “eles”, partes constitutivas da cultura do chãode-fábrica, segundo Willis (1991), era el em ento importante nessa sina. Na cultura do "el es", o go s to pela bebida, o propósi to de "fazer corpo mole" e o confronto com a autoridade imperavam como com portamentos não tolerados pelos gestores. A indicação de internação não só constituía forma de proteção à saúde, mas também uma estratégia administrativa. Não se trata, porém, de uma decisão planejada, tampo u co destituída da intenção de cuidados.

Nesse con texto, alguns enclausuramentos disciplinares começavam primei ro no seio da própria família e, posteriormente, no hospital, no inten to de melhorar, corrigir os excessos e fazer retornar os bons modos da vida regrada. Paralelamen te ao cuidado com a saúde, tentava-se en quadrar o trabalhador segundo as expecta tivas; ou seja, tra n s formá-lo em um su jeito com edido. Aqu eles que insistiam em resistir, sustentando o próprio sintoma, torn avam-se obj eto de cuidados especiais. Como uma espécie de reeducação disciplinar, começava-se, desse modo, a fusti gar a on i potência e a altivez daqueles que ousaram tran sgredir, deslocando o sujei to do domínio da fábrica ou do lar (em licença médica) para o hospital. O que transform ava a internação hospitalar também em espaço da bi opolítica, ou seja, a crescente implicação da vida natural do hom em nos mecanismos e nos cálculos do poder (Foucault, 1979,
1997; Agamben, 2002). Operava-se um en trel açamento tão íntimo en tre política, vida privada e cuidados médicos que a inves tigação era dificultada. Portanto, se a transformação do sofrimen to em adoecim en to represen tava a quebra da resistência dos trabalhadores, a hospitalização psiquiátrica era o cen á rio da vitó ra do poder institucional, num jogo em que se preparava a abertura do último e derradeiro ato, o da aposentadoria por invalidez.

\section{Rein serção profissional e aposentadoria por invalidez}

Após liberação médica para retorno ao trabalho, principalmente os psicóticos, mesmo esforçando-se para se readaptarem ao cargo, deparavam-se com en traves familiares que interferiam na sua reinserção, como no caso em que a esposa desejava que o mari do se apo sentasse. Ela está achando ótimo eu estar afastado. O grande sonho dela é que eu me aposentasse, agora, e fôssemos para o interior, onde os pais dela moram. Ela disse que faço coisas e depois não lembro, disse isso ao peri to (P. K., trabalhador do setor operacional, 41 anos). Com o prolongamento da licença médica, a aspiração pela aposentadoria $c$ rescia em algumas mulheres, en qu an to a autoestima de seus mari dos diminuía. Como estratégia para alcançarem seus objetivos, algumas acompanhavam os maridos à perícia médica, relatando situações que imaginavam provar a necessidade da aposentadoria: Eu não podia deixar que, depois de 18 anos de serviço, ele fosse mandado embora. Só aposentando. Quando ele entrou, era bom da cabeça, ficou assim de tanto fazer hora-extra e quando ouviu falar das novas máquinas que iam fazer o trabalho dele e que a em presa ia ser privatizada (esposa de P. K.). Na reinserção, os trabalhadores com diagnóstico de p si cose en frentavam dois grandes preconcei to s: eram incapacitados para o trabalho e agressivos. Com diagnósticoF.29, CID-10 (psicose), o referido empregado sem pre apresen tou excelen te desempenho, como pode ser constatado no depoim en to de seu su pervisor. Os três anos de afastamen to (após o surto), o estigma de doen te mental, entre os colegas, e os medos da esposa exigiram uma intervenção do serviço social, re ad a ptação funcional e ori entação aos supervis ores nos moldes de "trabalho protegido". Foram, assim, elaborados os medos e preconcei tos dos col egas, dos ge s tores e da esposa que, em seu depoimento, afirmou: Agora, ele está ou- 
tra pessoa, o serviço faz bem pa ra ele, está mais calmo, sente-se útil, a nossa relação melhorou bastante, já sinto mais confiança nele. Seria uma loucura se ele aposentasse. Imagine, o dia intei ro, ele em casa, sem o que fazer.

Nas famílias de trabalhadores joven s, a apos ent adoria parecia constituir "um mal necessário". Para a mãe de M. H., 27 anos, atendente comercial, afastado com diagnóstico de dependência química, a aposentadoria não seria um prêmio, seria uma taxação de incapacidade. Uma pessoa que se to rna incapaz com 27 anos pode ser uma tarja que ele venha carregar, né? Porque não pode ser benéfica. Ele vai ficar pior. Por outro lado, se ele não se curar e perd er o em prego? Como vai se manter e se tratar? Essa mãe imagin ava que o filho, uma vez demitido, dificilmenteobteria um novo emprego. A aposentadoria era a ga ra ntiado rendimento mensal e do tratamento através da empresa. Entretanto, percebia também que a aposentadoria precoce o estigmatizaria, de sobriga n do-o da respon sabilidade quanto à própria subsistência e da possibilidade de inve stir num processo de re a bilitação prof i ssional. Portanto as famílias con h eciam os desgastes sofridos pelas numerosas tentativas de readaptação. Em geral, os lugares oferecidos para "reabilitação", a pesar dos esforços dos prof i ssionais, eram limitados. Era comum o sujeito $s$ of rer novo afastamen to antes que o programa de reinserção se completasse. Para alguns gestores, aceitar o reabilitan do significava ter "meio trabalhador no setor". Sem uma perspectiva de "re acomodação" mais con sis tente, essas pessoas torn avam-se desacomodados crônicos, recebendo sucessivos afastamentos.

A aposentadoria por invalidez era, habitualmente, representada para as famílias como um bem. Muitos planos se faziam. Entre os mais velhos, era vista como uma recom pensa pelos anos de dedicação e uma libertação do compromisso cotidiano. Ac reditava-se que o equilíbrio familiar e a seg u rança financei ra seriam garantidos, haveria satisfação de todas as necessidades, tudo seria recolocado em seus devidos lugares. Então, imaginava-se um domínio sobre o futuro, enquanto a incerteza da permanência na em presa estava completamen te dissipada. E, com el a, o fantasma do de sem prego estava exorcizado: "Eles ficaram eufóricos com a notícia da aposentadoria, fomos festejar numa pizzaria" (W. A., gestor aposentado, 46 anos). Passada a fase de eu foria pela con quista do ben efício previdenciário, alguns en travam num quad ro depressivo. Haviam se torn ado inválidos não ape- nas para o trabalho, mas também para as funções de maridos, pais e cidadãos. Perdiam a identidade de trabalhador para assumir a de inválidos, chegando ao clímax do processo de tra $\mathrm{n}$ s formação do sof ri $\mathrm{m}$ en to em adoec i $\mathrm{m}$ en to. A trajetória de W. A. é ilu stra tiva desse proce sso. Após 25 anos de serviço, começou a trabalhar alcoolizado: eu não gostava de bebida, eu bebia para agüentar toda aquela pressão, era também para aliviar a culpa, tudo vi rou um círculo vicioso. As primeiras licenças médicas, a partir do diagnósti co de alcoolismo e depressão, seguidas da perda do cargo, agravaram o sof rim en todesse gerente administrativo. Como relata sua esposa, a aposentadoria foi a melhor opção: ele não podia nem passar na rua da empresa. Foi o maior alívio ter aposentado, se ele retornasse, seria mandado embora. Ele ficou sob o u so de medicamen tos e isto causava bloqueio. Ele não falava coisa com coisa. Deus providenciou esta apo sentadoria. Is to trouxe tranqüilidade (esposa de W. A.).

No entanto esse apaziguamen to inicial assumiu um rumo inteiram en te diferen te do sonhado, como revela a esposa: ele achou que, aposentando, ia viajar, ser livre pa ra fazer o que quisesse. Mas, em seguida, ele entrou em depressão. Só ficava deitado. Retirar-se do trabalho e refugiar-se nos pró prios aposentos, na condição de inválido, sob efei to de anti depressivos e ansiolíticos, constituíam formas de não se deparar com antigos conflitos que o "passar na rua da empresa" despert ava. A noção freudiana de sujeito do inconsciente, no caso desse gestor, atormentado pela culpa e pela pressão do trabalho - dimensões subj etiva e institucional, respectivamente -, foi substi tuída pela con cepção psicológica de indivíduo depressivo. O crescen te sucesso do diagnóstico de depressão deixa claro que as sociedades do fim do século 20 deixaram de privilegiar o conflito como núcleo normativo da formação subjetiva (Roudinesco, 2000).

\section{Considerações finais}

O sofrimen to, em sua ampla diversidade de sentidos e expressões, não pode equiparar-se, unicamente, ao sofrimento psíqu i co. Algumas de suas manifestações se assemelham, enquanto outras po s su em aspectos específicos. A acepção ampla do sofrimento como um bem do sujeito tem sido negligenciada, na atualidade, dificultando impulsionar o sujeito a uma ação tra n s formadora, bem como a atuação da saúde 
coletiva, in clu s iveem termos interdisciplinares. $\mathrm{Na}$ gestão do trabalho, a ausência de reconhecimento dessa peculiaridade do sof rimen to gera agravos, dificilmen te identificados, à saúde dos trabalhadores. Essa lacuna evidenciou-se, em nosso estu do, ao constatarmos os diversos de stinos dados às manifestações de sofrimen to no trabalho: a somatização, a psiquia trização, a medicalização, a licença médica, a hospitalização, a rei n s erção profis sional e a apo sen tadoria por invalidez. Esse movimento pode ser compreendido como uma das estratégias típicas da transição da sociedade disciplinar para a de controle, na perspectiva de Deleuze (1992). A flexibilidade com que o trabalhador transitava de um destino ao outro - e sem prazo definido - revela, porém, as constantes rei nvenções do sistema disciplinar. Essa elasticidade, facilmente confundida com liberdade, dificulta a percepção desses destinos como estratégias de con trole, remeten do o trabalhador a situações de maior ou menor sujeição. Se o tratamento medicamentoso domiciliar oferece, de início, n ovas liberd ades, comparado com a internação hospitalar, torna-se, posteriormente, uma forma de confinamento.

Personalizando e direcionando cada um desses destinos, constatamos a influência marcanteda figura feminina, a partir da posição de mãe ou de esposa, e de acordo com o seu desejo e a sua história. Na medicalização e na hospita- lização, a intervenção tinha uma visibilidade maior, deixando transparecer um misto entre atos que reforçavam o "fracasso do marido" e cuidados extremos com ele. Já em relação ao retorno ao cargo, uma vez elaborados os medos acerca da demissão, a participação da esposa demonstrou ser um recu rso para uma reinserção profissional bem-sucedida. Em todos os depoimentos das mulheres, a aposentadoria por invali dezapareceu como a melhor solução para a família, mas por curto período de tem po. Essas constatações sugerem a necessidade de um novo estudo, investigando a influência feminina no processo de transformação do sof rimento em adoecimento, na gestão do trabalho.

Em síntese, quebrar as lógicas e práticas que configuram uma dada com preensão do sofrimento que o tran sforma em adoecimento envo lve a ampliação de um deb a te na busca de altern a tivas que possam propiciar enfoques diferenciados e espaços adequados para oferecer cuidados específicos às manifestações do sofrimento. Alternativas que não conduzam aos destinos detectados no pre sen te estu do, mas a novos percursos, com diferen tes itinerários. Ac reditamos que o sofrimen to manifestado no trabalho possa ser descortinado, escutado e acolhido na dimensão em que ele vem tentando resistir, particularmen te diante das exigências decorren tes das mudanças atuais nos processos produtivos e na organização do trabalho.

\section{Colaboradores}




\section{Referências bibliográficas}

And re S 1995. A impo stu rapervers $a$. Ed. Zahar, Rio de Janeiro.

Aga m bem G 2002. Homo sacer: o poder soberano e a vida nua I. Ed. UFMG, Belo Hori zon te.

Bauman Z 1998. O mal-estar na pós-modernidade. Ed. Zahar, Rio de Jan eiro.

Bauman Z 2001. A modernidade líquida. Ed. Zahar, Rio de Jan ei ro.

Birman J 2000. Mal-estar na atualidade. Ed. Civilização Brasileira, Rio de Ja n ei ro.

Bo u rd i eu P 1994. No uvelles réflexions sur la domination masculine. Cahiers du Gedisst 11:91-104. Automne, Paris.

Brant L 2001. Sujeito e sofrimen to en tre trabalhadores que ocupam cargo gerencial. Dissertação de mestrado, Un iversidade Federal de Minas Gerais, Belo Horizonte.

Brant L 2004. Proce sso de tra n sformação do sof rimen toem adoecimen to na gestão do trabalho. Tese de do utorado. Escola Nacional de SaúdePública, Fundação Oswaldo Cruz, Rio de Ja nei ro.

Brant L \& Dias E 2004. Trabalho e sofrimen to em ges to res de uma em presa pública em reestruturação. $\mathrm{Ca}$ d ernos de Saúde Pública 20(4):942-949.

Coelho M \& Reis R 1998. Doenças músculo-esqueléticas de origem ocupacional dos membros superiores. Ed. Health, Belo Horizon te.

Dejours C 1992. A loucura do trabalho. Ed. Cortez, São Paulo.

Deleu ze G 1992. Conversações. Ed. 34, Rio de Ja nei ro.

Foucault M 1976 Hi sto ire de la sexualité: la volonté du savoir. Gallimard, Paris.

Foucault M 1979. Microfísica do poder. Ed. Graal, Rio de Janeiro.

Foucault M 1994. Dits et écrits. v. IV, Paris.
Foucault M 1997. Resumo dos cursos do Collège de France (1970-1982). Ed. Zahar, Rio de Ja nei ro.

Freud S 1920. Obras completas, v. 18. Além do princípio do prazer. Ed. Im ago, Rio de Janei ro.

Freud S 1924. Obras completas, v. 19. O problema econ $\hat{o}^{-}$ mico do masoquismo. Ed. Imago, Rio de Janei ro.

Freud S 1930. Obras completas, v. 21. O mal-estar na civilização. Ed. Imago, Rio de Ja n ei ro.

Freud S 1937. Obras completas, v. 23. Anál ise terminável e interminável. Ed. Im ago, Rio de Ja neiro.

Hanns L 1996. Dicionário Comentado do Alemão de Freud. Ed. Im ago, Rio de Janeiro.

Lazarus S 2001. Anthropologie ouvrière et enquêtes d'usine: état des lieux et problématique. Etymologie française 3(31):389-400.

Levy P 1997. O inexisten te impacto da tecnologia. Folha de S. Paulo, São Paulo, 17 ago. 1997. Caderno Mais, Autore s, p. 3.

Minayo M 1996. O desafio do conhecimento: pesquisa. Hucitec-Abra sco, São Paulo.

Min ayo M \& Deslan des(or gs.) 2002. Caminhos do pensamento. Fiocruz, Rio de Janei ro.

Rorty R 1999. Ensaios sob re Heidegger e outros. Ed. Relume-Dumará, Rio de Jan ei ro.

Rorty R 2002. Objetivismo, rel a tivismo e verdade. Ed. Relume-Dumará, Rio de Ja n ei ro.

Roudinesco E 2000. Por que a psicanálise? Ed. Jorge Zahar, Rio de Ja neiro.

Sen n ett R 2000. A corrosão do caráter. Ed. Record, Rio de Jan eiro.

Spinoza B 1983. Da origem e da natureza das afecções, pp. 175-221. In Ospensadores. Ed. Abril Gultural, São Paulo.

Valadares J 2000. Qualidade do espaço e habitação humana. Ciência \& Saúde Col etiva 1 (5):83-98.

Willis P 1991. Aprendendo a ser trabalhador. Ed. Artes Médicas, Porto Al egre.

Artigo apre s en tado em 4/10/2004

Aprovado em 25/02/2005

Versão final apre s en tada em10/03/2005 